\title{
INDUCTION OF NEWLY QUALIFIED TEACHERS: LIMITS, NEEDS AND OPPORTUNITIES
}

\author{
Mihaela Stîngu \\ Mihaela.stingu@gmail.com \\ University of Bucharest, Romania
}

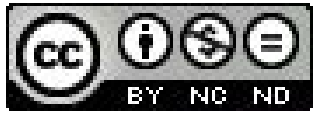

\begin{abstract}
In Europe induction is becoming a very important phase of teacher training, but still little is said about its limitations and pitfalls. The purpose of this paper is twofold. First, it analyzes both a series of limitations and pitfalls encountered in the implementation of the induction process. Second, it identifies precautions that need to be taken into consideration when implementing such programmes, in order to determine some opportunities of improving the induction process. With the intention of achieving the purpose stated above, we used a case study approach to investigate the Estonian induction programme that has been implemented since 2004. We have chosen this case because it is recognized in Europe as one of the best induction programmes and it bears a resemblance to the Romanian educational system.

The results of our study point to a number of problems that arise in various aspects regarding mentors, newly qualified teachers, school culture and a university approach. Taking those problems into account, we will propose how they could be remedied.
\end{abstract}

Key words: newly qualified teachers, induction programme, teacher professional development, mentoring.

\section{CONTEXT OF THE STUDY}

The European Commission requires that all member states "make appropriate provision for all new teachers to participate in a programme of induction (early career support) offering both professional and personal support during their first years in a teaching post" (European Commission, 2010a, p. 5). In 2009 alone only 11 member states implemented an induction programme for new teachers and only in seven of these states was the induction programme was implemented atall four levels of education: pre-primary, primary, general lower and upper secondary (Education, Audiovisual \& Culture Executive Agency of the European Union [EACEA], 2009). In 2012, however, the number of states involved in this project increased to 13 (EACEA, 2012). Even if the number of states which decided to implement such programmes is increasing, there is a lack of coherence at the European level regarding the design and implementation process which can be observed in the following two areas:

- the role of induction in the professional development of teachers;

- the significance of this period for teachers (formative vs. evaluative). 
The European Commission's Staff issued a working document entitled Developing coherent and system-wide induction programmes for beginning teachers - a handbook for policymakers (2010), which stresses the fact that the Estonian induction system is an example of good practice and recommends that other states should follow it. Because it is recognized in Europe as one of the best induction programmes and it bears a close resemblance to the Romanian educational system, we find it relevant to analyze the Estonian induction system for newly qualified teachers (NQTs) as basis for the development of a similar system in Romania.

\section{PURPOSE OF THE STUDY}

This study discusses different aspects regarding the design and implementation of such a system. It also seeks to identify a series of limitations and pitfalls encountered in the implementation of the induction process and suggest precautions that need to be taken into consideration when implementing such programmes, in order to determine some opportunities to improve the induction process.

\section{METHODOLOGY}

Our research strategy involves an individual case study. This approach allows us to explore and analyze the complexity of designing and implementing an induction programme at a national level. For the purpose of our study, we can assume that the most appropriate definition of the case study is the one stated by an observer in Wilbur Schramm: "The essence of a case study (...) is to try and clarify a decision or a set of decisions: why were those decisions taken, how were implemented and with what results?" (1971, cited in Yin, 2005, p. 29). We can supplement this definition by adding that our case study additionally intends to identify the implications of such a decision (implementing the induction system in Estonia) on the stakeholders and on the entire system of training and professional developing of teachers in Estonia.

The structure that we used is a standard one. We will start with a review of the literature on the topic and relevant educational policy documents. Then, we will discuss the methods used, results, analysis of data and causal connections. The data analysis will be carried out in terms of stakeholders, that is, educational science experts, teacher trainers, teachers, mentors and managers.

In order to fulfill the above stated aims, we used the following methods:

\section{Analysis of documents:}

- Legislative framework on the professional development of teachers within the Estonian educational system;

- Scientific articles written by experts in educational sciences involved in the design, implementation and evaluation of the induction year (books, articles, $\mathrm{PhD}$ thesis);

- European Commission reports relevant for this study 
Figure 1. Stages of the case study: Implementation of the induction year for novice teachers in Estonia

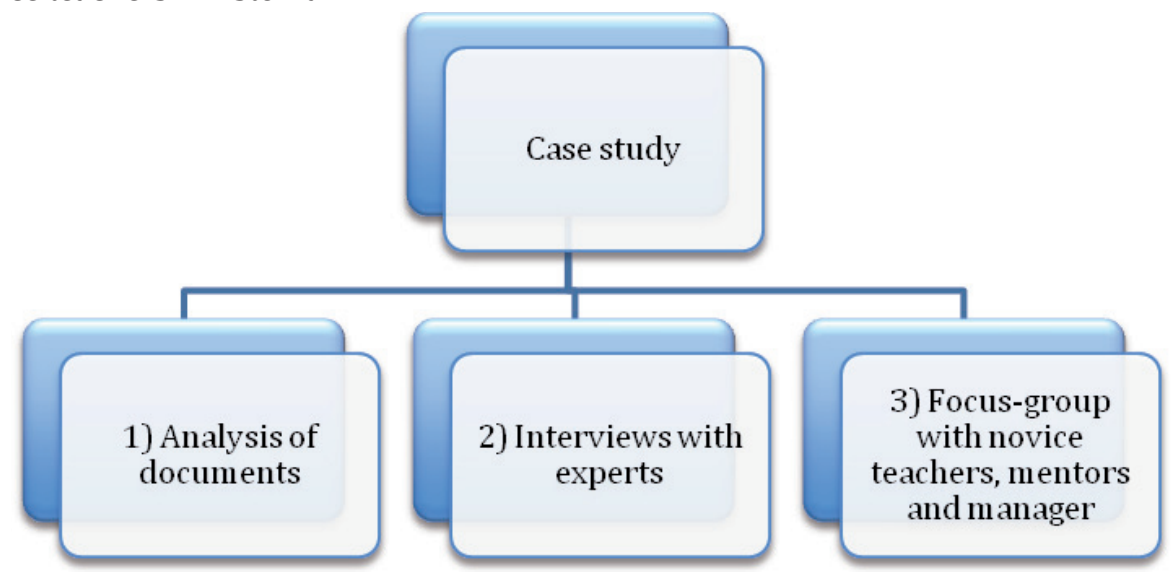

2. Interviews with experts. In the following analysis of documents, we conducted a series of interviews with the experts involved in the design, implementation and evaluation of the induction year. The key experts were: the Vice-Rector for Development at Tallinn University and the initiator of the induction programme in Estonia (Expert 1); Head of the Centre for Continuing Education at Tallinn University (Expert 2); member of the Department of Teacher Education at Tallinn University and member of the implementation team working on the induction programme (Expert 3 ).

The main objectives of the interviews were: (1) to identify problems which arose in the process of designing and implementing the induction year; (2) to disseminate the results obtained during the evaluation of the induction year; (3) to makes some suggestions for improving the model; (4) to identify some risks and precautions that ought to be taken into consideration when designing and implementing an induction year for novice teachers. All three interviews followed the same set of general questions, but in each interview the focus was on the experts' role in the induction programme.

3. Focus-group with teacher, mentors and school coordinator. In order to identify and analyze the school's perspective, we conducted a focus-group comprising a mentor, a manager (school coordinator of the programme) and those teachers who are or have been involved in the programme. The school where we carried out the focus-group has been involved in the programme since the pilot phase in 2002/2003. We chose this method and decided on a heterogeneous group in order to be able to explore the group dynamics and the culture of communication, as well as to identify the relationships that are established.

The objectives of the focus-group were: (1) to identify the critical aspects with which novice teachers have to deal during their first year of teaching; (2) to determine the degree to which the induction programme supports those teachers in order to overcome these problems; (3) to identify the ways in which novice teachers receive personal, social and professional support; and (4) to draw some suggestions for improvement of the model from the novice teachers' perspective. 


\section{RESULTS}

Overview of initial training and continuous professional development of teachers in Estonia

The Estonian Teacher Education Strategy 2009-2013 (The Estonian Ministry of Education and Research, n.d) states that in the 2008/2009 school year, there were employed 14,682 teachers, who were on average 45 years old, and an approximate of 200 newly qualified teachers at the beginning of the school year (Eisenschmidt, Poom-Valickis \& Karner, 2011).

The initial training of teachers takes place at universities and in colleges, except for pre-primary teachers, who are additionally trained in institutes. Initial training programmes for subject and class teachers at basic and upper secondary schools are organized at two universities : Tallinn University and Tartu University.

As shown in Figure 2 (EACEA, 2012), primary and secondary school teachers have to obtain a bachelor degree in a field of study (180 ECTS) and a master's degree (120 ECTS), and they are also required to complete their pedagogical studies (60 ECTS) (Eisenschmidt, Poom-Valickis \& Karner, 2011).

Figure 2. Required level and minimum length of initial teacher education for teachers from pre-primary to upper secondary education (ISCED 0, 1, 2 and 3), and the length of the induction period, 2010/11 (EACEA, 2012).

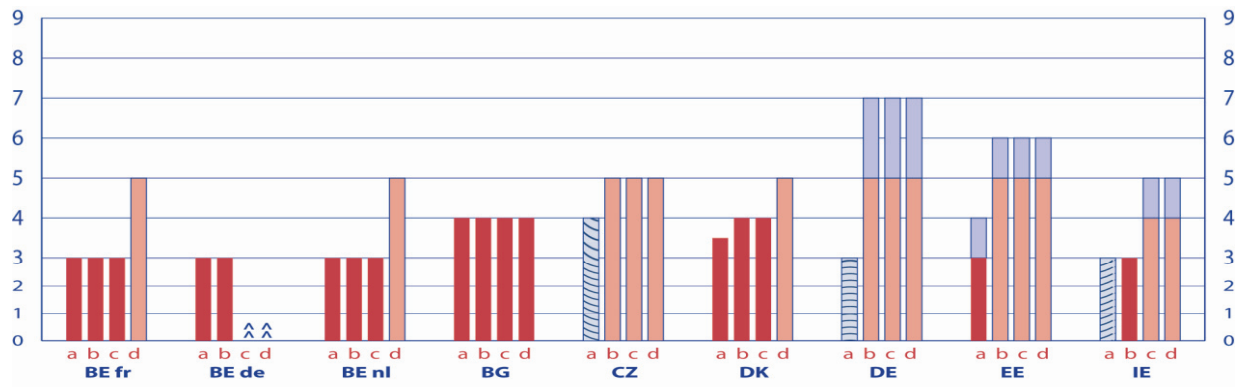

To teach at level:a -Pre-primaryb -Primaryc -Lower Secondary d -Upper Secondary Qualification needed:

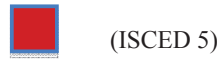

ISCED 6

In Estonia, in order to continue professional development, teachers must undergo at least a 160-hour training within five years (European Commission, 2010b). The market of continuous training for teachers is free. Teachers can participate in programmes that can be provided by a wide range of providers, from the Ministry of Education and Research or regional/local authorities to private providers or NGOs which have appropriate accreditation for the programmes they deliver.

\section{Induction of newly qualified teachers in Estonia}

Design and implementation. The induction programme for newly qualified teachers in Estonia was first launched in 2002/2003 in the Haapsalu College (Tallinn University) in cooperation with a number of schools in the western part of Estonia. 
During the next year (2003/2004), a group of experts from Tallinn University and Tartu University, teachers and managers established the details of implementing this programme at the national level. In 2004/2005 (European Commission, 2010a), this national programme was implemented in Estonia and applied to primary and secondary teachers. In 2005/2006, it also concerned pre-primary and vocational teachers also (Fransson \& Gustafsson, 2008) with the length of one year, as demonstrated in Figure 2.

As stated by the European Commission document Developing coherent and system-wide induction programmes for beginning teachers - a handbook for policymakers the main objectives of the induction programme in Estonia include supporting the adjustment of novice teachers to school as an organization, developing basic competences in new teachers and providing support in solving problems (European Commission, 2010a).

Considering the tendencies in teachers' professional development in Estonia, Eisenschmidt (2008) argues that the education of teachers must be divided into three dimensions: knowledge and professional development, social and personal (Figure 3).

Eisenschmidt (2008) also highlights the fact that in accordance with this dimension, the process through which newly qualified teachers receive support has to focus on three areas: the development of professional competencies, the development of a professional identity and socialization in the profession. In the induction model introduced in Estonia, two components are promoted: mentoring and a support programme for novice teachers atuniversities.

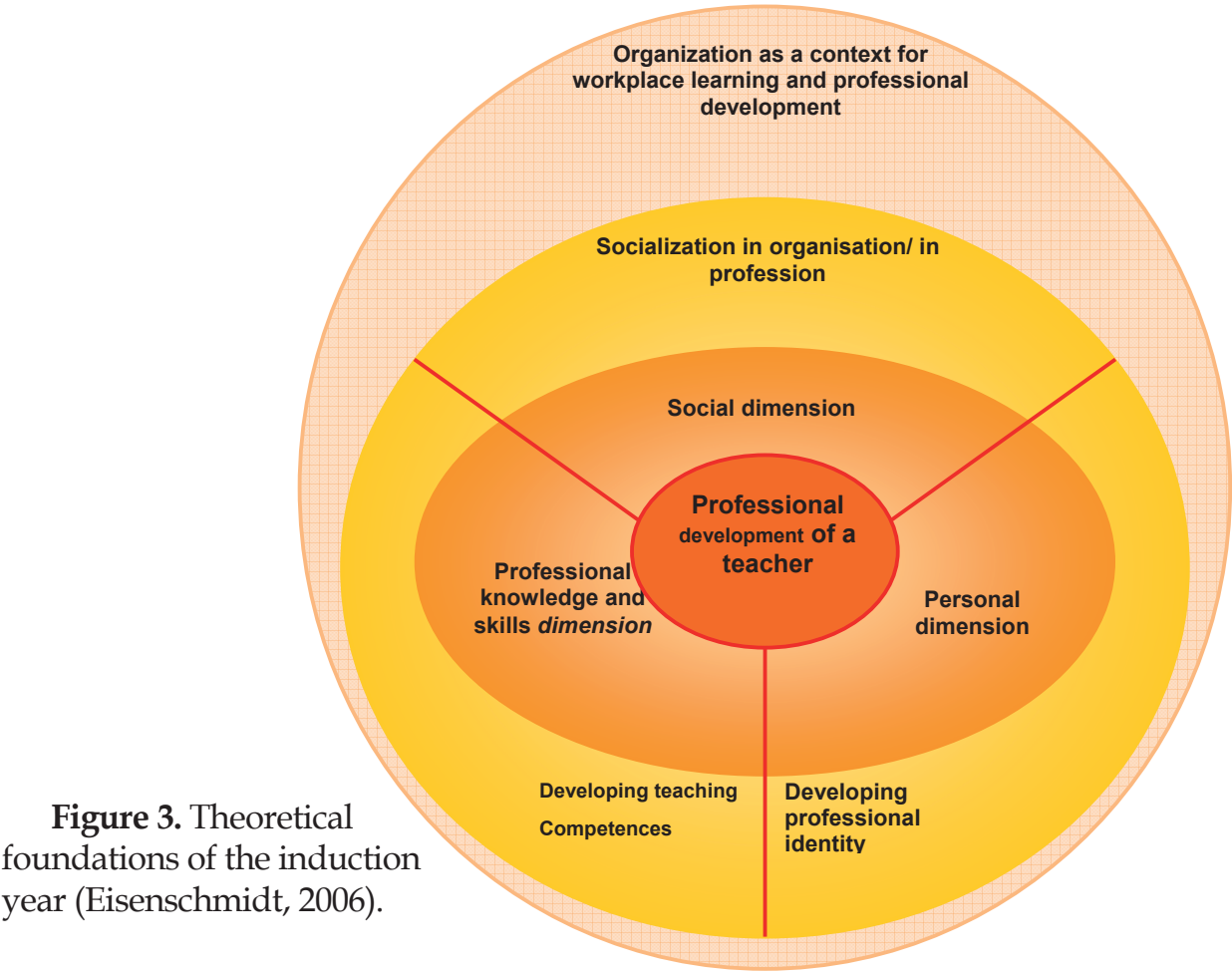


Monitoring and evaluation. The European Commission document (2010a) states that the induction programme in Estonia is evaluated by universities and is permanently monitored. The results of this evaluation are, in turn, transmitted to teacher education institutes in the form of feedback to improve the quality of their curriculum. The whole process of monitoring and evaluation is financed by the Ministry of Education and Research (European Commission, 2010a). Finally, the results from the monitoring and evaluation processes are analyzed by experts in educational science, mentor trainers and school managers (Eisenschmidt, Poom-Vlalicks \& Karner, 2011).

Monitoring and evaluation questionnaires are applied to newly qualified teachers, mentors and school managers. For newly qualified teachers, such a questionnaire is used "four times a year (...) in order to identify the changes and evaluate their level of competencies" (Expert 1), which also has the purpose to identify "the extent to which mentors provide support (...) and to evaluate the programmes provided by universities" (Expert 1).

Partners: roles and responsibilities. In this section, we identify the role of partners in the induction programme and analyze the scope of their responsibilities, in order to be able in the sections that follow to point out a number of limitations and pitfalls from a stakeholder's point of view.

Eisenschmidt (2006) identifies four stakeholders which are concerned in the induction programme: school manager, mentor, newly qualified teacher, a university centre for induction. In one of the documents of the European Commission (2010a), it is stated that the Ministry of Education and Research is one of the institutions that finances the courses and the monitoring process, both of which take place in university centres.

A glance at our analysis reveals that two important aspects come into play when it comes to the collaboration between stakeholders and the Ministry: " a good collaboration between partners helped in overcoming some difficulties (...) and this [financial resources] make possible regular meeting between partners, the seminars and is a positive aspect because this way we can improve it [induction programme]" (Expert 2).

The role of school managers is to coordinate the implementation of the induction programme in the school they lead. Their responsibilities include: (1) registering newly qualified teachers in the university centres for induction; (2) selecting a mentor for each teacher; (3) emphasizing and developing the cooperation between the newly qualified teacher and the mentor; (4) allowing mentors to participate in training courses; (5) establishing the work load of mentor's and new teacher's tasks in order to permit cooperation; and (6) evaluating at the end of the academic year newly qualified teachers according to the Professional Standard for Teachers (Talilina Ülikool, 2008).

Because the emphasis of the induction year is placed on developing both the capacity of the school as an organization and the experience gained throughout the eight years of implementation at the national level, there was a need to develop training for school managers in certain aspects: "We now have advanced courses for school managers that focus on ways to use mentoring not just for newly qualified teachers, but for all teachers in the school (...)" (Expert 1).

Another key point in the implementation of the induction programme is the capacity of managers to develop a school culture of communication: "(...) I can say 
that in our school you can ask anyone for help and they will help you" (Mentor); "I believe that this induction year helps in creating this climate. We learn to ask for help, but also give help" (Teacher 1).

In what mentors are concerned, they play a very important role in the induction programme for newly qualified teachers. In Estonia, in order to become a mentor, you have to undergo a training course that lasts eight days (6 ECTS). It is financed by the Ministry of Education and Research (Eisenschmidt, Poom-Vlalicks, \& Karner, 2011). The purpose of this course is to develop a common understanding of what mentoring involves and to develop a series of competencies that the mentor should possess in order to properly support newly qualified teachers. An interesting fact regarding the Estonian model is that mentors can do two activities in parallel: take training courses and, at the same time, be a mentor. The experts interviewed believe that this is a good practice because it puts mentor's learning into practice: “(...) I believe that it is a very good approach because it is based on cognitive and experiential learning theories (...), is in fact more efficient than to go through an entire course and forget some things... and maybe after a few years you will have a newly qualified teacher to mentor..." (Expert 1).

As mentioned before, university centers for induction are essential partners in developing this kind of programme. Such centers have two main purposes: to hold "reflection" seminars for newly qualified teachers and to run training courses for mentors. In one of the sections that follow, we will try to look at those seminars and their contents from the perspective of the university experts and from the perspective of teachers. Evaluating the seminar that they have participated in, teachers believe that the meetings afforded opportunities for reflection and personal development: "For me the seminars meant more personal development (...)" (Teacher 2); "At the end of the seminar, everybody is thinking of their own problem and discover their own solution (...)" (Teacher 1); "And sometimes, when you are there, you find cases... and your problems don't seem that big anymore" (Teacher 4).

From the experts' point of view, this seminar aims at creating opportunities for new teachers to share their experiences with colleagues who face the same problems and to learn from each other: "The seminars are for personal reflection (...) I believe that when newly qualified teacher come to university centers, they create a kind of network (...). This is the place where they can share experiences, good or bad, reflect on them, and also to plan the next steps..." (Expert 2).

Initial teacher training, Induction, Continuing professional development. Induction programmes for newly qualified teachers can bridge the gap between initial and continuing professional development for teachers.

One of the objectives of the induction of newly qualified teachers is to ensure feedback for initial teacher training institutions. In this way, we can stress the idea that induction programmes can offer relevant information about the quality of initial teacher training programmes only if the providers of such programmes are actively involved in induction. Discussing the link between initial education and induction in the Estonian model, Poom-Valickis (2007) highlights the importance of analyzing initial teacher training programmes from the point of view of teachers and also on the level of pedagogical 
competence of teachers. He also stresses the importance of the Estonian Professional Standard for Teachers (Opetaja, 2005). "In Estonia, the curriculum for initial training is based on this standard. When we plan the curriculum, we try to incorporate the competences from this standard, which represents also the starting point for induction (...)" (Expert3).

In establishing the link between initial training and induction, there is yet another aspect that plays a very important role, namely, partnership between universities (as providers of training for teachers) and schools (as workplaces for teachers), and their shared vision on teacher education and development. "I believe that is well known the debate in literature about the dissatisfaction of schools in what initial teacher training is concerned... and universities consider that school culture is not very supportive for new teachers (...)" (Expert 1).

One aspect that we need to take into consideration in this process of professionally developing teachers is the fact that the induction period should not be viewed as a way to overcome the shortage in initial training, but to be viewed as a different stage in this process.

In Estonia, continuing professional development for teachers is concerned as the first stage of the induction process. Eisenschmidt, for instance, analyzed a number of theoretical aspects that underlined the design of the induction model in Estonia, through which it is highlighted that "The prerequisite for the continuous development of a teacher is the readiness to develop oneself, to analyze one's work" (Eisenschmidt, 2006, p. 10). Hence, in the first year of teaching, the basic competences are developed and a professional self-concept is formed. Actually, the ability to self-reflect is one of the important bases for professional growth (Schön, 1983; Calderhead, 1988; Korthagen, 1999; Harrison et al., 2005, cited in Eisenschmidt, 2006).

Taking into consideration the fact that in Estonia the market of continuing professional training and development for teachers is free and that education providers can be both from the public or private sector, the influence of induction on the courses offered by those providers is difficult to monitor and control, even though it is universities that use results obtained from the monitoring process in order to improve the continuing professional training courses for teachers.

\section{LIMITATIONS AND PITFALLS}

In this section, we will analyze the limitations and pitfalls of the induction programme, identified by experts, mentors, teachers and school leaders.

As mentioned before, mentors play a central role in the induction programme. The difficulties encountered in this area are limited to mentors' attitude towards mentoring. This attitude can derive from a lack of understanding of the mentor's role or from a lack of interest in this kind of activity and responsibility. "The first problem we encounter is that mentors act like teachers... it is very important to identify the ways through which we can change this behavior" (Expert 1). "The mentor doesn't have to give the fish to new teachers, they have to give them the proper tools to catch it" (Expert 3).

Another problem encountered in implementing the induction programme was that mentoring activities were not integrated in a day-to-day schedule of mentors and newly qualified teachers. As a result, mentors felt isolated in their activities and 
in the need for feedback from each other and the school leaders: "...the problem is that they [mentors] feel very lonely...school managers appoint mentors and then they aren't interested in the way the activity is carried out... it's an isolated task and not integrated in the organization's activities (...)" (Expert 1).

As far as university seminars are concerned, one pitfall in implementing the induction year was the understanding of the role of seminar coordinators. Being academics it was difficult not "to teach", but to create a safe environment for teachers to discuss and reflect. "When we started in 2004, there were not so many that would be capable of conducting these meetings because this is something different from the lecturers (...) So the role of the seminar conductor is to make teachers reflect and express their reflections to the other colleagues" (Expert 2).

As in the case of mentors, it is an issue of adapting to a different role than the one they were used to. The same difficulties are encountered by newly qualified teachers when they shift their roles from student teachers to teachers. "At first they [newly qualified teachers] are so focused on themselves, they are only behind the desk and they can't see what is happening... but now... they see more and notice different things" (Mentor).

Another issue encountered in new teachers' behavior is their resistance to change, their attachment to some practices they learned and their reluctance to reflect. As one of the experts remarked, "reflection is a learning process... and learning is always a little bit "painful«. You may discover things that you don't want to and you have to change your behavior or your acting patterns (...) the reflection process is serious thinking and it needs time (...)" (Expert 1).

\section{INSTEAD OF CONCLUSIONS...PRECAUTIONS}

By analyzing above stated aspects, we can arrive at a number of conclusions regarding the precautions that should be taken into consideration when designing and implementing an induction programme. We found two main vulnerable areas that we can address: resources and the training of university seminar coordinators and mentors.

With regard to resources, a first step must be taken to ensure a stable partnership between all stakeholders (schools, universities, Ministry), starting from the designing stage, in order for them to take control of the programme and understand their roles and responsibilities from the very outset. Also in terms of resources, a very important component is the financial one, which is needed for monitoring the evaluation of the programme, in order to permanently improve and develop the programme.

Another turning point regards the understanding of roles and responsibilities of each person involved, with a specific focus on mentors and university seminar coordinators. As far as mentor training is concerned, it should focus more on enhancing mentors' understanding of their role and changing their ways of acting "like a teacher" in order for them to be able to offer personal and professional support. The process of supporting NQTs should proceed through permanent feedback and reflection. As mentioned before, university seminar coordinators need to have a deeper understanding of what their role is and to detach themselves from their day to day activities as lecturers. Both mentors and seminar coordinators raise the issue of adapting to a different role from the one they were used to, which is a process that also needs time and effort on their part. 
The results of our analysis suggest that there are a number of difficulties encountered in various aspects that concern mentors, newly qualified teachers, school culture and university approach. Those difficulties can be overcome by accurately defining everybody's liabilities and ways in which they can fulfill them.

\section{REFERENCES}

Education, Audiovisual \& Culture Executive Agency of the European Union (2009). Key Data on Educationin Europe. Retrieved from http://eacea.ec.europa.eu/education/eurydice/documents/key_ data_series/105en.pdf

Education, Audiovisual \& Culture Executive Agency of the European Union (2012). Key Data on Educationin Europe. Retrieved from http://eacea.ec.europa.eu/education/Eurydice/documents/key_ data_series/134EN.pdf.

Eisenschmidt, E. (2006). Implementation of Induction Year for Novice Teachers in Estonia. Tallinn University Dissertations on Social Sciences, 25. Abstract retrieved from http://e-ait.tlulib.ee/103/1/eisenschmidt_eve2.pdf.

Eisenschmidt, E. (2008). Induction and the teacher professional development: an Estonian project. Retrieved from http://www.tlu.ee/files/arts/1930/induccf38944444024c0d80fe4f192604f406e.pdf.

Eisenschmidt, E., Poom-Vlalicks, K., Karner, A. (2011). Support programme for novice teachers: benefits and challenges. In: P. Picard, L. Ria (eds.). Beginning teachers: a challenge for educational systems - CINDREE Yearbook 2011. Lyon: Institut francais de l'Education.

Eisenschmidt, E., Poom-Valickis, K. , Koster, K. (2008). Implementation of induction year programme in educational institutions in Estonia. Tallinn: Tallinn University.

Estonian Ministry of Education and Research (2000). Framework requirements for teacher education in Estonia. Tallinn.

Estonian Ministry of Education and Research (2003). National Development Plan for Teacher Education. Tallinn.

Estonian Ministry of Education and Research (n.d). The Estonian Teacher Education Strategy for 2009-2013. Retrieved April 28, 2013, from www.hm.ee/index.php?0\&popup=download\&id=10278.

European Commission (2010a). Developing coherent and system-wide induction programmes for beginning teachers - a handbook for policymakers. Staff Working Document SEC. Retrieved from http:/ /ec.europa. eu/education/news/doc/sec538_en.pdf.

European Commission (2010b). Teachers' Professional Development: Europe in international comparison Europe in international comparison. An analysis of teachers' professional development based on the OECD's Teaching and Learning International Survey (TALIS). doi: 10.2766/63494.

Fransson, G., Gustafsson, C. (eds.) (2008). Newly qualified teachers in Northern Europe: Comparative perspectives on promoting professional development. Gavle: Gavle University Press.

Huisman, J., Santiago, P., Hogselius, P., Lemaitre, M. A., Thorn, W. (2007). Reviews of Tertiary Education-Estonia. OECD Report. Retrieved from http://www.oecd.org/education/skills-beyond-school/39261460.pdf.

Jensen, B., Sandoval-Hernandez, A., Knoll, S., Gonzales, E.J. (2008). The Experience of New Teachers Results from TALIS 2008. OECD Report. Retrieved from http://www.oecd.org/edu/school/49846877.pdf.

Õpetaja V kutsestandard, 2005. Koostanud ja kinnitanud hariduse kutsenõukogu [Teacher's Professional Standard V, 2005. Complied and adopted by Education Professional Council]. Retrieved from http://www. hm.ee/index.php?044930.

Picard, P., Ria, L. (eds.) (2011). Beginning teachers: a challenge for educational systems - CINDREE Yearbook 2011. Lyon: Institut francais de l'Education.

Poom-Valickis, K. (2007). Novice teachers' professional development across their induction year. Tallinn University. Dissertation on Social Sciences, 33. Tallinn: Tallinn University Publisher.

Talilina Ülikool (2008). Implementation of induction year programme in educational institutions in Estonia. Retrieved from http:/ / e-ait.tlulib.ee/103/1/eisenschmidt_eve2.pdf.

Yin, R. (2005). Studiul de caz: Designul, colect areasi analiza datelor [Case Study: Design, data collection and analysis]. Iasi: Polirom. 